\title{
Effect of Cyclic Wetting and Drying on the Microstructure of Slip Zone Soils in Huangtupo Landslide
}

\author{
Wu Yiping ${ }^{1,2}$, Li Linwei ${ }^{1}$, Feng Xiaola ${ }^{1, *}$, Zhang Rong $^{3}$ and Ákos Török ${ }^{4}$ \\ ${ }^{1}$ Faculty of Engineering, China University of Geosciences, Wuhan 430074, China \\ ${ }^{2}$ Three Gorges Research Center for geo-hazard, Ministry of Education, Wuhan 430074, China \\ ${ }^{3}$ China Railway Major Bridge Reconnaissance \& Design Institute Co., Ltd., Wuhan 430056, China \\ ${ }^{4}$ Department of Construction Materials and Engineering Geology, Budapest University of Technology and Economics, Budapest 1111 , \\ Hungary
}

Received 19 May 2016; Accepted 21 September 2016

\begin{abstract}
The stability of reservoir slopes is critical to the safe operation of reservoirs and is intensely affected by cyclic wetting and drying (W-D) caused by water level fluctuation. A new cyclic W-D test was performed on remoulding specimens to explore the influence of cyclic W-D on the microstructure of slip zone soils. Firstly, the unsaturated compacted specimens were prepared and subjected to cyclic W-D using a self-manufactured permeameter and a constant temperature oven. Secondly, the primary driver of the changes in soil microstructure was determined via X-ray diffraction. Thirdly, the evolution during each W-D cycle was characterised via mercury intrusion porosimetry and scanning electron microscopy. Results show that under the effect of seepage pressure, the microstructure of slip zone soils periodically varies along with increasing W-D cycle. Such change is primarily attributed to the swelling and shrinkage of clay minerals. The pore size distribution of the specimens shifts from a mono-peak pattern to a multi-peak pattern because of the extension of drying shrinkage cracks, which indicates that cyclic W-D can induce more defects in soil microstructure. This study reveals the effect of cyclic W-D on slip zone soil microstructure. These findings encourage further research into the failure mechanism of reservoir slopes under the effect of water level fluctuation.
\end{abstract}

Keywords: Soil microstructure, Water level fluctuation, Cyclic wetting and drying, Slip zone soils, Reservoir slope

\section{Introduction}

The stability of reservoir slopes has become a major issue amongst engineering geologists and hydraulic engineers, and its failure often leads to catastrophic life and property losses. The cyclic wetting and drying (W-D) caused by water level fluctuation greatly affects the stability of reservoir slopes. When the full operation of the Three Gorges Dam increases the water level to its peak value of $175 \mathrm{~m}$, the slip zone soils in Huangtupo Riverside $\mathrm{I}^{\#}$ Landslide undergo complex cyclic infiltration and drainage because of water level fluctuations. Cyclic W-D can alter the microstructure of slip zone soils, specifically the preferential orientation and distribution of particles, the arrangement and distribution of pores, the fractal dimension and structure of aggregates, the contact between particles and aggregates and the contact amongst pores. Furthermore, the changes in the microstructure of slip zone soils can alter the hydraulic and mechanical behaviour of soils, including their shear strength, permeability, compressibility, water-holding capacity and bearing capacity. Ultimately, these changes adversely affect the stability of reservoir slopes and the safe operation of reservoirs as can be observed in the Vajont Landslide in Italy and the Qianjiangping Landslide in China. Therefore, investigating

the effect of water level fluctuation on the microstructure of slip zone soils may offer great application potential and high

*E-mail address: fx1649@126.com

ISSN: $1791-2377$ @ 2016 Eastern Macedonia and Thrace Institute of Technology. All rights reserved. research value. By using vacuum saturation to simulate the wetting path, some scholars had investigated the effects of wetting path and cyclic W-D on soil microstructure. However, wetting path under the influence of water level fluctuation is an infiltration process that involves seepage pressure, and previous studies were unable to reflect the actual circumstance of slip zone soils. Although other scholars revealed the effect of infiltration process on soil microstructure, their investigations did not consider cyclic W-D. Therefore, vacuum saturation must be replaced with a new wetting method to reveal the effect of cyclic W-D on the microstructure of slip zone soils.

\section{State of the art}

Soil microstructure has increasingly been investigated over the past 90 years to interpret the hydraulic and mechanical behaviour and physical properties of soils. This research area has considerably developed along with the continuous emergence of novel techniques, particularly mercury intrusion porosimetry (MIP) and scanning electron microscopy (SEM), which have been widely employed in quantifying the microstructure of soils.

MIP quantitatively represents the microstructure of materials with interconnected pores, and the pore size distribution (PSD) of porous materials can be inferred from MIP results. Numerous engineering geologists have considered PSD a significant structural element with broad application in geotechnical engineering and correlated this 
element with the macroscopic properties of rocks and soils. Romero and Simms [1] summarised the extant PSD literature and found that the type of compaction for clay, the saturated water permeability, the frost-heave properties and the changes in the macroscopic volume of soils were closely associated with PSD. Many studies [2-10] indicated that PSD was affected by many factors, such as dry density, moulding water content, suction, number of weathering cycles, hydro-mechanical paths, chemical reactions, dissolution of solid phases and biological processes. MIP results were also used to predict the water retention properties and permeability of specimens [2], [11-13].

SEM is the most promising qualitative method for observing the porosity and arrangement of aggregates, particles and pores in unsaturated soils. The electron micrographs from SEM arbitrarily present 2D images of the small areas of specimens and can be used to reveal the microstructure of soils. Using SEM, Katti and Shanmugasundaram [14] observed a considerable reduction in particle size during the wetting process as a result of the breakdown of clay aggregates, whilst Lin et al. [15] investigated the increase in sample stiffness induced by structural variation and related such increase with lime/cement or sludge/fly ash stabilisations. Specifically tailored for wet samples, environmental scanning electron microscopy (ESEM) preserves the natural characteristics of specimens as much as possible for the further testing. Zhang et al. [16] used ESEM to investigate the alterations in the microstructure of dual-porosity tropical soil during drying and wetting paths.

Many scholars have combined SEM and MIP in examining the microstructure of soil and rock samples. Garcia-Guinea et al. [17] used both techniques to observe the composition and deterioration of Calatorao biogenic stone. Tang and Yan [18] examined the effect of freezethaw on the hydraulic conductivity and microstructure of soft soils, and found that freeze-thaw decreased the void ratio and specific pore area of these soils yet increased their average pore diameter and hydraulic conductivity.

The aforementioned studies have widely applied MIP and SEM to analyse the microscopic characteristics of soils under various conditions and mostly established a correlation between their microscopic and macroscopic properties. Theoretically, when the wetting path is an infiltration process with seepage pressure, the effect of cyclic $\mathrm{W}-\mathrm{D}$ on soil microstructure is essentially the same as that of water level fluctuation. However, previous studies considered vacuum saturation as the wetting path, which could not reflect the actual effects of water level fluctuation. Some scholars investigated the effect of infiltration on soil microstructure, but their investigations were not related to cyclic W-D. Therefore, this work used a self-manufactured permeameter in place of the conventional vacuum saturation to make the cyclic W-D closely reflect infiltration and drainage under natural conditions.

The rest of this paper is arranged as follows. Section 3 describes the material selection, the fundamental properties of materials, the preparation of specimens and the experimental procedures and conditions. Section 4 analyses the testing results and discusses the problems encountered in the experiments. Section 5 concludes the paper.

\section{Methodology}

Reconstituted specimens of slip zone soils from Riverside I Landslide were used as research objects and subjected to cyclic W-D tests. Firstly, the specimens were prepared under similar initial conditions, and a constant temperature oven and a self-manufactured permeameter were used to perform cyclic $\mathrm{W}-\mathrm{D}$ tests under various cycles and seepage pressures. Secondly, two representative specimens were subjected to X-ray diffraction (XRD) tests to analyse the primary material factor that induced the changes in soil microstructure. Thirdly, the evolution of the specimen microstructure, including the variations in the PSD, porosity and structure of soil particles, were determined via MIP and SEM.

\subsection{Material selection}

As shown in Fig. 1, Huangtupo Landslide is located in Badong County, Hubei Province, China, and is just $69 \mathrm{~km}$ away from the Three Gorges Dam. Huangtupo Landslide is one of the most important landslides in the Three Gorges Reservoir and mainly comprises Garden Spot Landslide, Substation Landslide, Riverside I $I^{\#}$ Landslide and Riverside II ${ }^{\#}$ Landslide.

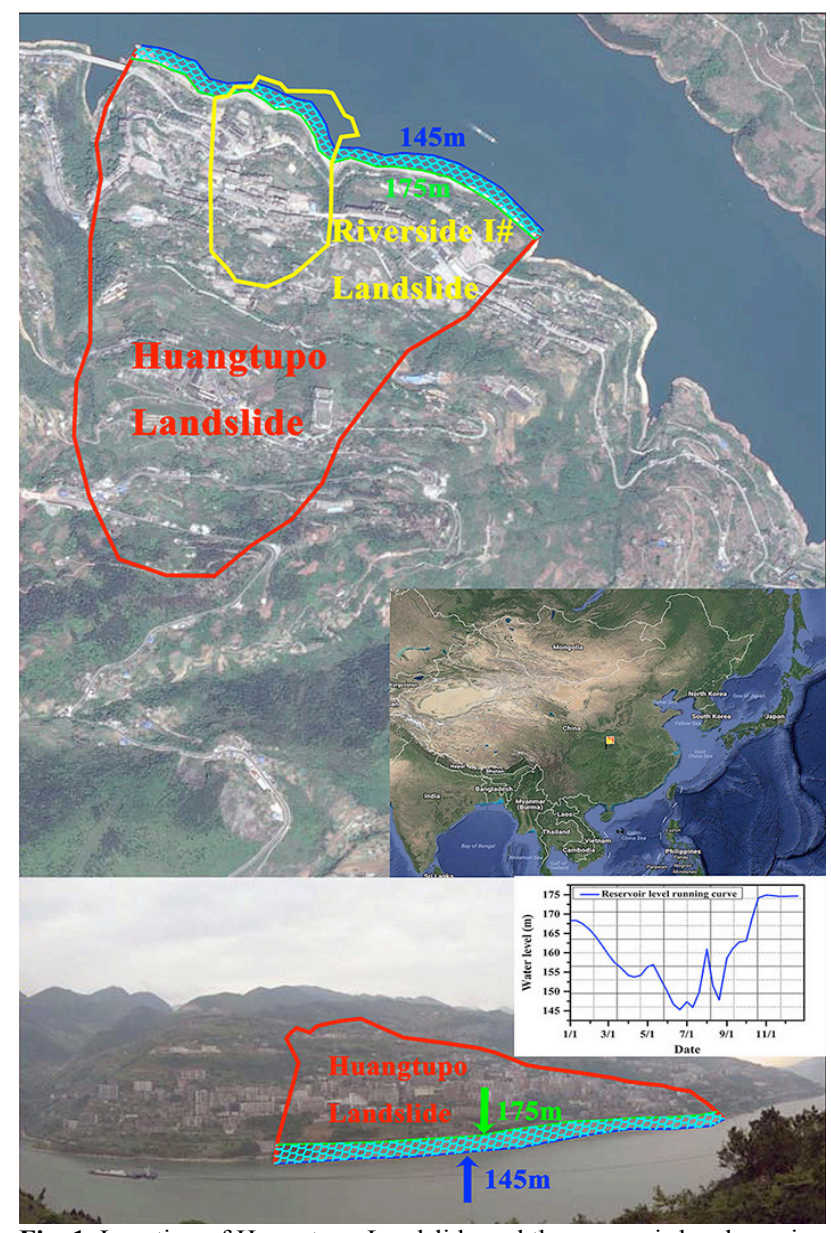

Fig. 1. Location of Huangtupo Landslide and the reservoir level running curve of Three Gorges Reservoir

Huangtupo Landslide was separated from Sandaogou Valley, and its riverside part was steeper than its rear part. The forepart on the west side was covered by Riverside I Landslide, while the rear part of Riverside $I^{\#}$ Landslide was overlain by Garden Spot Landslide [19].

Riverside $\mathrm{I}^{\#}$ Landslide was selected as a research object. The western borderline of this landslide extended from Badong New Dock to Shennongxi High School and County Hospital, whilst its eastern borderline was connected to Riverside II $^{\#}$ Landslide. This landslide had a $32.4 \mathrm{~m}^{2} \times 10^{4}$ $\mathrm{m}^{2}$ land area and a $22.55 \mathrm{~m}^{3} \times 10^{6} \mathrm{~m}^{3}$ volume, and mainly 
comprised rock blocks and fragments with cataclastic material and clay [20], [21].

Under the effect of the periodic fluctuation in the reservoir level as shown in Fig. 2-1, Riverside $\mathrm{I}^{\#}$ Landslide, specifically its foot, is affected by cyclic infiltration and drainage. These reduplicative actions not only alter the microstructure of the slip zone soil but also form internal and surface drying shrinkage cracks. Given the reduced strength of the soil and the erosion of microcracks, the periodic fluctuation in the reservoir level can result in the failure of the slip zone soil and the instability of the slope. Consequently, reconstituted specimens of slip zone soils from Riverside $\mathrm{I}^{\#}$ Landslide were selected as research objects to examine the microstructure evolution of slip zone soils during cyclic W-D.

\subsection{Material properties}

The slip zone of Riverside $\mathrm{I}^{\#}$ Landslide mainly comprised fine-grained soils with many coarse-grained particles. As shown in Fig. 2, fine fraction (clays+slits), sands and gravels accounted for $45.21 \%, 13.83 \%$ and $40.96 \%$ of undisturbed slip zone soils, respectively. Table 1 showed the results from the routine soil tests of undisturbed slip zone soils.

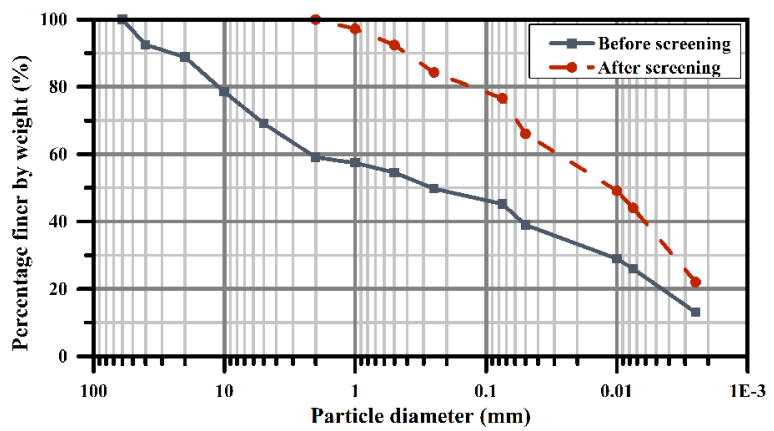

Fig. 2. Particle size accumulation curves of undisturbed slip zone and reconstituted soils

Table 1. Basic physical properties of undisturbed slip zone soil in Riverside I $\mathrm{I}^{\#}$ Landslide

\begin{tabular}{|c|c|c|c|}
\hline Specimen & \multicolumn{2}{|c|}{ Physical properties } & Value \\
\hline \multirow{6}{*}{ Undisturbed slip zone soil } & \multicolumn{2}{|c|}{ Water content: $\%$} & 15.6 \\
\hline & Density: $\mathrm{g} / \mathrm{cm} 3$ & Natural & $\begin{array}{l}2.03 \\
1.79\end{array}$ \\
\hline & \multirow{4}{*}{\multicolumn{2}{|c|}{$\begin{array}{c}\text { Degree of saturation: } \% \\
\text { Liquid limit: } \% \\
\text { Plastic limit: } \%\end{array}$}} & 75.5 \\
\hline & & & 25.95 \\
\hline & & & 18.36 \\
\hline & & & 7.59 \\
\hline
\end{tabular}

\subsection{Specimens preparation and cyclic $W-D$ test}

The undisturbed slip zone soils of Riverside $I^{\#}$ Landslide were manually crushed into fine powder, and the gravels $(\mathrm{d}>2 \mathrm{~mm})$ in undisturbed soils were removed. Fig. 2 illustrated the cumulative particle size distribution of the reconstituted soil specimens, more than half of which comprised the fine fraction (clays+slits).

The specimens had a $39.1 \mathrm{~mm}$ diameter, $80 \mathrm{~mm}$ height, $15.6 \%$ initial moisture content and $2.03 \mathrm{~g} / \mathrm{m}^{3}$ density. The distinction of density was controlled within $0.02 \mathrm{~g} / \mathrm{m}^{3}$. A total of 39 specimens were prepared according to the above standards, amongst which three were used as control specimens, whilst the other 36 were subjected to the cyclic $\mathrm{W}-\mathrm{D}$ test.

The cyclic $\mathrm{W}-\mathrm{D}$ test included a permeability (wetting) test and a constant temperature drying test. The wetting test was performed using a self-manufactured permeameter (Fig.
3) with three seepage pressures (i.e., 100, 200 and $300 \mathrm{kPa}$ ). A constant temperature oven was used in the drying test to

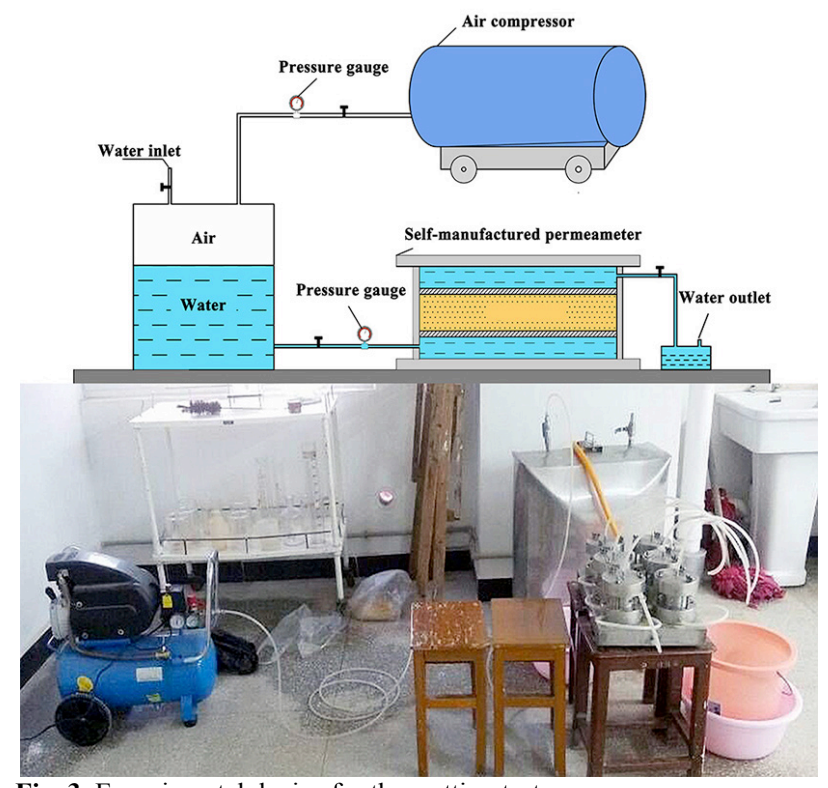

Fig. 3. Experimental device for the wetting test

simulate the drainage of the slip zone soil, with each drying test performed for $24 \mathrm{~h}$ under $30^{\circ} \mathrm{C}$. One wetting test and one drying test constituted a complete cycle, and the cyclic W-D test was performed four times under each seepage pressure. The specimens were labelled according to their seepage pressures and cycles. For instance, the specimen under the effect of $100 \mathrm{kPa}$ seepage pressure and one $\mathrm{W}-\mathrm{D}$ cycle was labelled 'Sample 100-1', the specimen under the effect of $200 \mathrm{kPa}$ seepage pressure and four W-D cycles was labelled 'Sample 200-4' and the control specimens were labelled 'Sample 0-0'.

\subsection{Investigation of mineral composition}

Samples 0-0 and 200-4 were subjected to XRD tests using AXS D8-Focus (Bruker Optics, Germany). The diffraction patterns of these specimens were recorded at $40 \mathrm{kV}$ and 40 $\mathrm{mA}$, and the measuring range of $2 \theta$ started from $5^{\circ}$ to $70^{\circ}$ with a scanning speed of 0.05 seconds/step and a step size of $0.01^{\circ}$. The measurement was performed at $24{ }^{\circ} \mathrm{C}$ and $36 \%$ humidity.

\subsection{Investigation of soil microstructure evolution}

The non-wetting liquid without external pressure, such as mercury, is not automatically immersed in solid pore. A certain amount of pressure is applied to mercury to overcome the surface tension of soil and push the mercury into the soil pores. According to the Washburn equation [1], a definite pressure value corresponded to a specific pore size. Given that the intrusion of mercury was equivalent to the pore volume, MIP was performed as follows to investigate the changes in the pore during cyclic W-D:

$P_{H g}=-\frac{4 \sigma_{H g} \cos \theta_{n w}}{x}$

Where, $P_{H g}$ denotes the pressure applied to the mercury for obtaining the throat diameter $x$ inside a pore, $\sigma_{H g}$ denotes the surface tension of mercury and $\theta_{n w}$ denotes the contact angle between the mercury and pore walls. Each soil has a unique $\theta_{n w}$ value. Specifically, natural clay, bentonite, 
sodium bentonite, kaolinite/illite and montmorillonite have values of $140^{\circ}, 140^{\circ}, 141.38^{\circ}, 147^{\circ}$ and $139^{\circ}$, respectively [5]. In this MIP test, $\theta_{n w}=130^{\circ}$ and $\sigma_{H g}=0.485 \mathrm{~N} / \mathrm{m}$.

The MIP equipment, Auto Pore IV9500 (Micromeritics Instrument Corporation, USA), can provide a maximum pressure of $228 \times 10^{3} \mathrm{kPa}$, and the detecting range of pore diameters ranging from approximately $360 \mu \mathrm{m}$ to $5 \times 10^{-3} \mu \mathrm{m}$. To ensure that the microstructure of the specimens remained unchanged as much as possible, the specimens were freezedried using liquid nitrogen to remove all pore fluid and vapour before conducting the MIP test.

\subsection{Observation of soil microstructure}

The field emission equipment SU8010 (Hitachi, Japan) was used as the SEM test equipment. For experimental accuracy and universality, the observation surfaces of specimens were randomly selected and observed under a magnification of $800 \mathrm{X}$. The clearest SEM images were selected for analysis. Before the SEM test, the 13 specimens were freeze-dried to remove all pore fluid and vapour, and the fresh observation surfaces of specimens were sprayed with carbon to increase their conductivity.
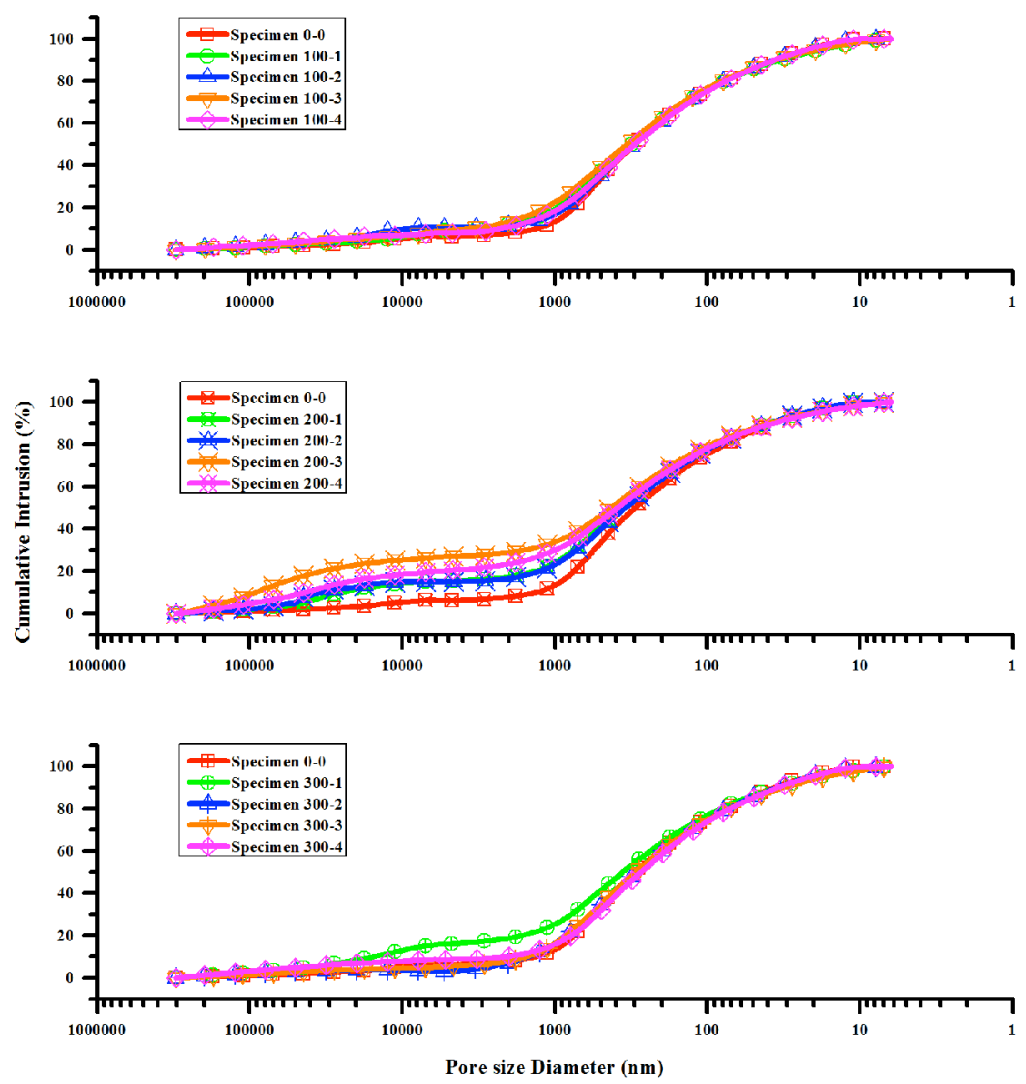

Fig.4. Cumulative pore size distribution curves of 13 specimens

\section{Result Analysis and Discussion}

\subsection{Mineral compositions of specimens}

Table 2 showed the XRD test results. Two specimens mainly comprised quartz, calcite, illite and montmorillonite (chloritisation), with quartz having the highest content and montmorillonite having the lowest. Nevertheless, these specimens had dissimilar mineral contents, which might be attributed to inevitable errors in the specimen preparation.

Table 2. Mineral composition and relative contents of Samples 0-0 and 200-4

\begin{tabular}{c|c|c|c|c}
\hline \multirow{2}{*}{ Specimen } & \multicolumn{3}{|c}{ Phase composition: \% } \\
\cline { 2 - 5 } & Quartz & Calcite & Illite & Montmorillonite (chloritization) \\
\hline $0-0$ & 44.65 & 22.82 & 31.58 & 0.95 \\
$200-4$ & 41.26 & 21.68 & 33.76 & 3.29 \\
\hline
\end{tabular}

The cyclic W-D test was a short process that ignored the variations in the mineral composition of soils. Quartz and calcite showed almost no variations during cyclic W-D, thereby leaving the specimen microstructure unaffected. However, illite and montmorillonite were strongly affected by water because of their swelling and shrinkage, which were the primary material factors that altered the microstructure of the slip zone soil.

Two findings are worth noticing. Firstly, the swelling and shrinking properties of clay minerals were reversible, and the changes in the microstructure of the specimens might be cyclic in nature. Secondly, the cyclic swelling and shrinking procedures significantly affected the pore characteristics of the slip zone soil. When the specimens were dried in a constant temperature oven, a network of drying shrinkage cracks easily formed on their insides and surfaces.

\subsection{Evolution of porosity and PSD}

As illustrated in Fig. 4, the cumulative distribution curves of the 13 specimens were obtained via MIP. These curves were divided into five parts, namely, micro pore $(0.005 \mu \mathrm{m}$ to 0.4 $\mu \mathrm{m})$, small pore $(0.4 \mu \mathrm{m}$ to $1 \mu \mathrm{m})$, middle pore $(1 \mu \mathrm{m}$ to 5 $\mu \mathrm{m})$, big pore $(5 \mu \mathrm{m}$ to $30 \mu \mathrm{m})$ and large pore $(360 \mu \mathrm{m}$ to 30 $\mu \mathrm{m})$.

As shown in Fig. 5, the variation in the porosity of the specimens under the effect of $100 \mathrm{kPa}$ and $300 \mathrm{kPa}$ seepage pressures exhibited a bimodal downward fluctuating trend. 
By contrast, under the effect of $200 \mathrm{kPa}$ seepage pressure, the porosity of the specimens exhibited a phased increasing trend, which was mainly attributed to the significant increase in the size of the large pore.

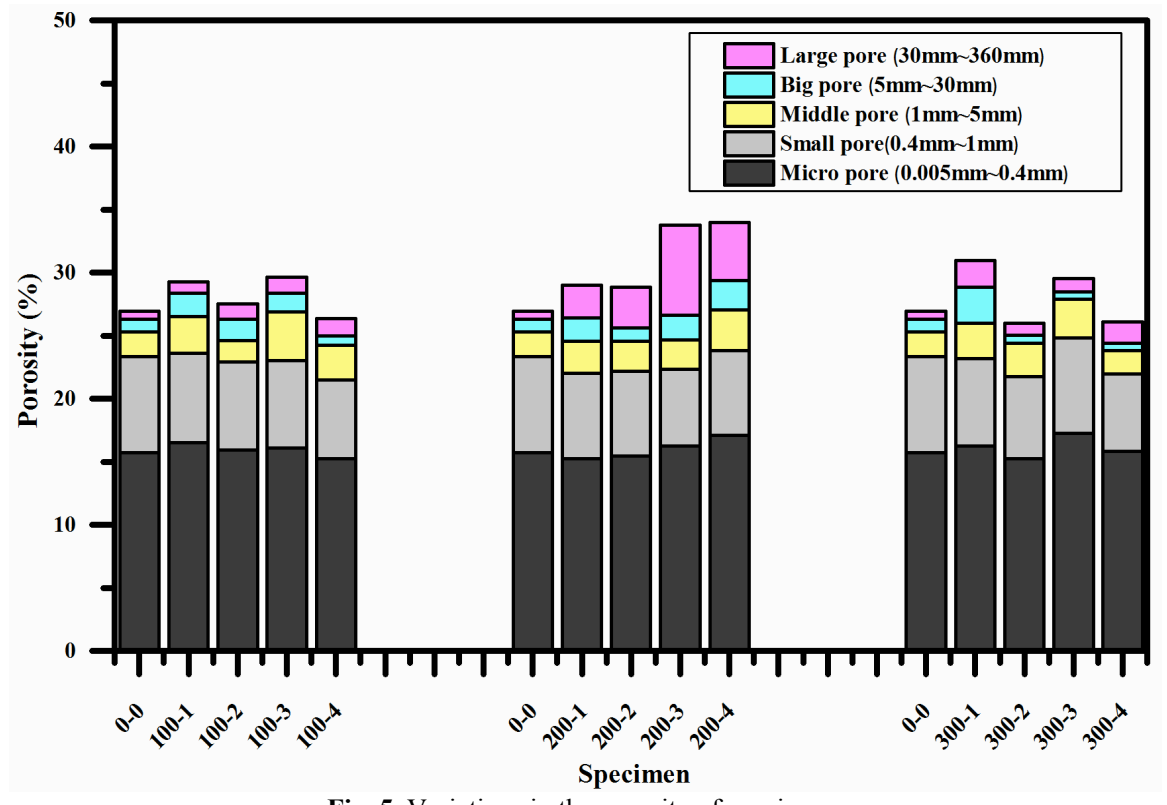

Fig. 5. Variations in the porosity of specimens

Table 3. Relative changes of specimens' porosity (compared with Sample 0-0)

\begin{tabular}{|c|c|c|c|c|c|c|c|}
\hline \multirow{2}{*}{$\begin{array}{l}\text { Seepage } \\
\text { Pressure } \\
: \mathbf{k P a}\end{array}$} & \multirow[b]{2}{*}{ Cycle } & \multicolumn{5}{|c|}{ Variations in porosity of five parts: $\%$} & \multirow{2}{*}{$\begin{array}{l}\text { Changes in } \\
\text { porosity: \% }\end{array}$} \\
\hline & & $\begin{array}{c}\text { Micro pore } \\
(0.005 \mu \mathrm{m} \sim 0.4 \mu \mathrm{m})\end{array}$ & $\begin{array}{c}\text { Small pore } \\
(0.4 \mu \mathrm{m} \sim 1 \mu \mathrm{m})\end{array}$ & $\begin{array}{c}\text { Middle pore } \\
(1 \mu \mathrm{m} \sim 5 \mu \mathrm{m})\end{array}$ & $\begin{array}{c}\text { Big pore } \\
(5 \mu \mathrm{m} \sim 30 \mu \mathrm{m})\end{array}$ & $\begin{array}{c}\text { Large pore } \\
(360 \mu \mathrm{m} \sim 30 \mu \mathrm{m})\end{array}$ & \\
\hline \multirow{4}{*}{100} & 1 & 0.73 & -0.54 & 0.95 & 0.86 & 0.24 & 2.24 \\
\hline & 2 & 0.22 & -0.63 & -0.25 & 0.65 & 0.57 & 0.56 \\
\hline & 3 & 0.38 & -0.70 & 1.91 & 0.51 & 0.61 & 2.71 \\
\hline & 4 & -0.50 & -1.35 & 0.82 & -0.27 & 0.70 & -0.60 \\
\hline \multirow{4}{*}{200} & 1 & -0.47 & -0.82 & 0.55 & 0.85 & 1.96 & 2.07 \\
\hline & 2 & -0.28 & -0.87 & 0.42 & 0.07 & 2.57 & 1.90 \\
\hline & 3 & 0.50 & -1.47 & 0.37 & 0.92 & 6.52 & 6.83 \\
\hline & 4 & 1.38 & -0.89 & 1.27 & 1.31 & 3.97 & 7.05 \\
\hline \multirow{4}{*}{300} & 1 & 0.52 & -0.70 & 0.86 & 1.87 & 1.47 & 4.02 \\
\hline & 2 & -0.48 & -1.13 & 0.70 & -0.32 & 0.26 & -0.97 \\
\hline & 3 & 1.51 & -0.04 & 1.15 & -0.44 & 0.42 & 2.60 \\
\hline & 4 & 0.10 & -1.49 & -0.12 & -0.36 & 0.98 & -0.89 \\
\hline
\end{tabular}

Fig. 5 showed the dissimilar trends and extents of variations in the porosity of five districts. However, some of these districts might follow similar variation patterns under the effect of different seepage pressures. As shown in Table 3 , the small pore followed a declining trend. The middle, big and large pores of 12 specimens were almost larger than those of Sample 0-0. The micro pore of 12 specimens was mostly larger than that of Sample 0-0. Although the limitations of MIP might cause its measurement results to be not precise enough, the trends in the variation of specimen porosity were still worth examining. The increased porosity was mainly attributed to the development of the micro, middle, big and large pores, whilst the decreased porosity was mainly attributed to the decrement of the small pore.

Fig. 6 clearly indicated that more than $60 \%$ of the pore diameter was distributed between $6 \mathrm{~nm}$ to $1000 \mathrm{~nm}$, and their dominating pore diameters were various. The PSD under the effect of $100 \mathrm{kPa}$ and $300 \mathrm{kPa}$ seepage pressures remained virtually unchanged along with the increasing $\mathrm{W}-$ D cycle. However, the PSD under the effect of $200 \mathrm{kPa}$ seepage pressure shifted from a mono-peak pattern to a multi-peak pattern.
The variations in the porosity and PSD of the specimens were primarily attributed to the coupling effect of two factors. Firstly, the wetting test resulted in the aggregation and transportation of particles. These particles formed aggregates under the effect of water molecules, and the distance between these aggregates increased along with the swelling of illite and montmorillonite, thereby increasing the porosity of the specimens. Seepage also transported tiny granules, which transporting capacities were associated with the increase of seepage pressure. The transportation of particles decreased the small size pore and increased the large size pore, thereby increasing porosity. However, the transportation of particles could decrease porosity when the drying process made these aggregates highly unstable. Many aggregates were destroyed in the following cycle, and the destroyed aggregates greatly outnumbered the newly formed aggregates, thereby decreasing porosity. Secondly, the drying process could result in water loss and shrinkage of illite and montmorillonite, thereby shrinking the voids, reducing the aggregates connection force, increasing the small size pore, decreasing the large size pore and forming shrinkage cracks. Zhang et al. [16] observed the formation 
of a well-developed network of microcracks on clay during drying, and most of these expanded cracks were healed in the subsequent hydration. The unhealed drying shrinkage cracks can result in excessive mercury incursion and develop the large size pore, thereby increasing the porosity of the specimens. Under the effects of seepage in subsequent wetting tests, these cracks might also turn into real pores, thereby permanently increasing the porosity of the specimens and inducing more defects in soil microstructure.
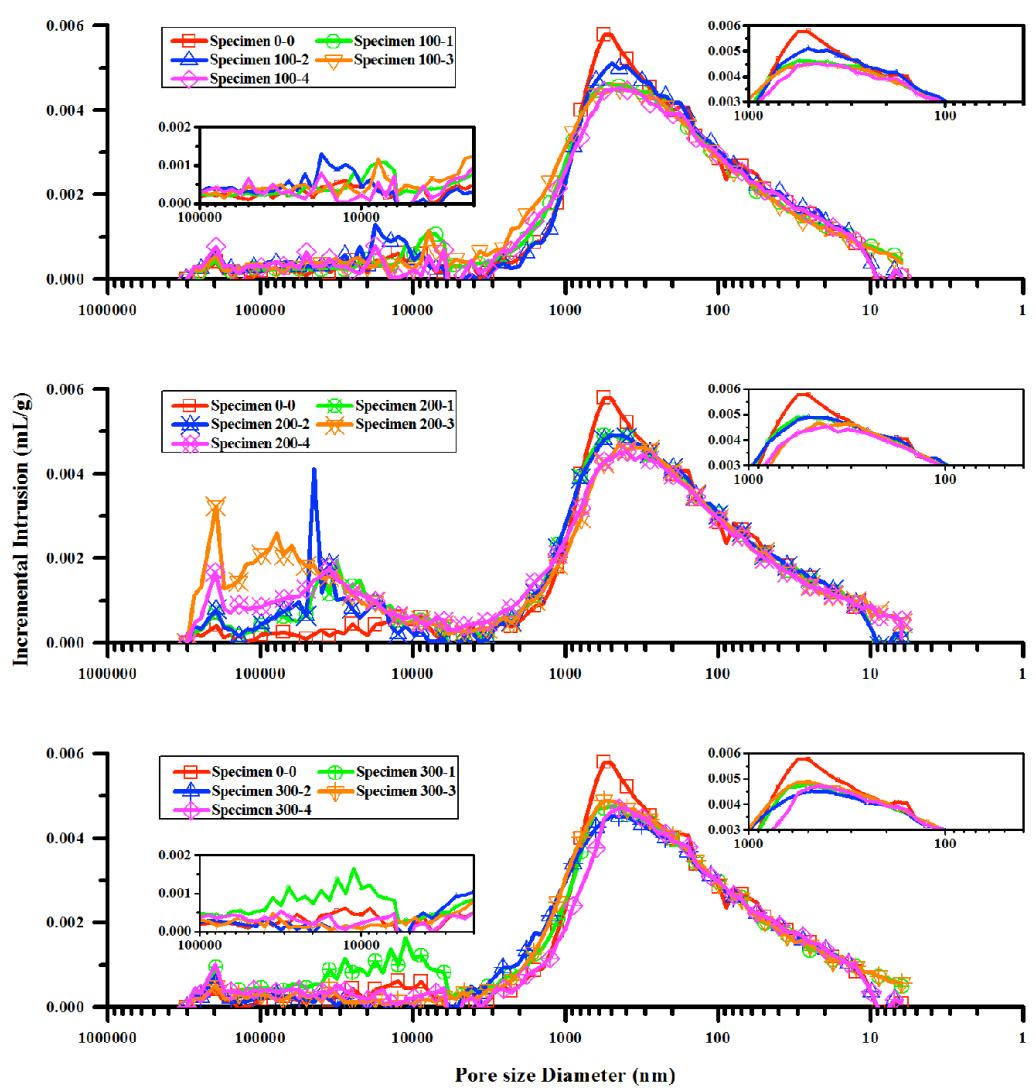

Fig. 6. Pore size distribution of 13 specimens

\subsection{Microstructure characteristics of aggregates}

Given their characteristics and limitations, SEM and MIP may yield different results. The SEM micrographs randomly presented 2D images of small areas of the specimens, which could not directly reflect the microstructure of the soil and could only be used to observe the local features of this microstructure. However, the SEM results could be combined with those of MIP to reveal the microstructural evolution of slip zone soils during cyclic W-D

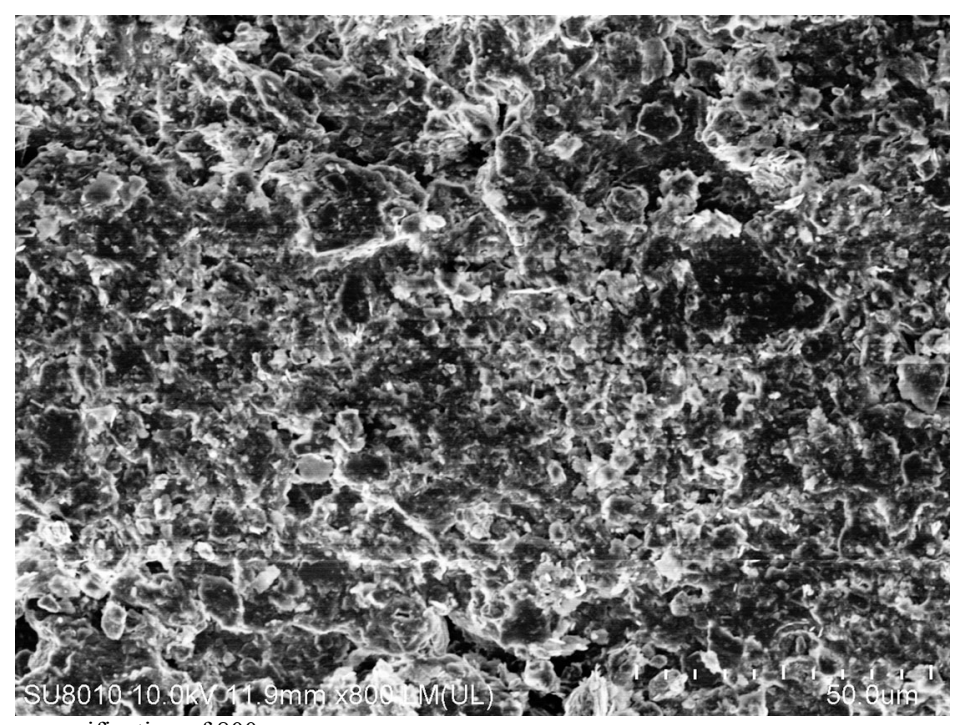

Fig.7. SEM image of Sample $0-0$ at a magnification of $800 \mathrm{x}$ 


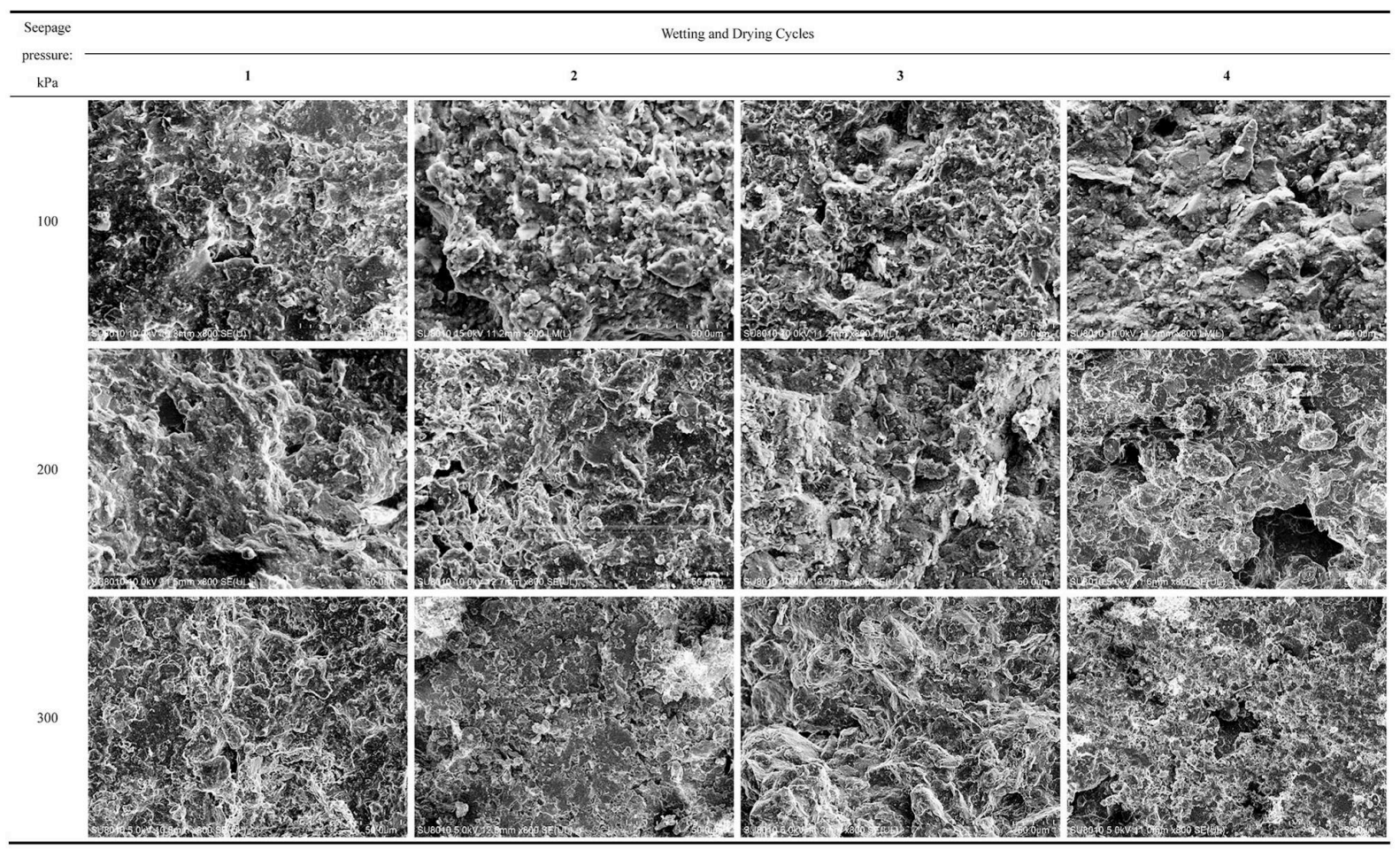

Fig. 8. SEM images of other 12 specimens at a magnification of $800 \mathrm{x}$

As shown in Fig. 7, the SEM image of Sample 0-0 indicated that control specimens had few aggregates and almost no large size pores, which corresponded to the original microstructure of remoulding specimens.

Fig. 8 displayed the SEM images of the 12 other specimens. The size and quantity of aggregates, specifically those of specimens under the effects of $100 \mathrm{kPa}$ and $300 \mathrm{kPa}$ seepage pressures, fluctuated along with increasing W-D cycle. The aggregates in the odd cycle were larger than those in the even cycle, whilst their quantities exhibited the opposite trend. Consistent with the MIP results, these fluctuations suggested that the cyclic $\mathrm{W}-\mathrm{D}$ of slip zone soils was always accompanied by the destruction and emergence of aggregates.

\section{Conclusion}

To reveal the influence of water level fluctuation on the microstructure of slip zone soils, a new cyclic W-D test was performed on the remoulding slip zone soils. The primary material factors resulting in the alterations of soil microstructure were investigated via $\mathrm{XRD}$, whilst the evolution of the specimen microstructure was characterised via MIP and SEM. The following conclusions were obtained:

(1) By neglecting the changes in the mineral composition of slip zone soils, the swelling and shrinkage properties of clay minerals were identified as the primary factors that induced the variations in soil microstructure under the effect of cyclic W-D.
(2) Under the effect of cyclic W-D, slip zone soils were subjected to the effects of cyclic infiltration and drainage, which periodically altered their microstructure. The periodic changes in slip zone soil microstructure mainly occurred in the local part of the soil microstructure features. These variations could be attributed to the emergence of drying shrinkage cracks that could be gradually healed in the subsequent wetting test.

(3) When the drying shrinkage cracks were not fully healed and continued to be infiltrated, the cyclic W-D induced more defects in the soil microstructure. Therefore, the soil microstructure might be destroyed, and the stability of slopes at the reservoir bank might be reduced.

This work not only facilitates to reveal the failure mechanism of reservoir slopes but also offers theoretical support to evaluate the stability of reservoir slopes and prevent landslides at reservoir banks. However, given the limitations of the experimental techniques and the lack of research in this area, the effect of cyclic W-D on the microscopic behaviour of slip zone soils has not been studied thoroughly. This research area still has many unsolved issues, such as the $3 \mathrm{D}$ and dynamic evolution of soil microstructure. Further research must be conducted to address these issues.

\section{Acknowledgements}

The study was supported by the National Natural Science Foundation of China (No.41272307 and No.41572278).

\section{References}

1. Romero, E., Simms, P. H., "Microstructure Investigation in Unsaturated Soils: A Review with Special Attention to Contribution of Mercury Intrusion Porosimetry and Environmental Scanning Electron Microscopy", Geotechnical \& Geological Engineering, 26(6), 2008, pp. 705-727.
2. Simms, P. H., Yanful, E. K., "Predicting soil-water characteristic curves of compacted plastic soils from measured pore-size distributions", Géotechnique, 52(4), 2002, pp. 269-278.

3. Romero, E., "A microstructural insight into compacted clayey soils and their hydraulic properties", Engineering Geology, 165(20), 2013, pp. 3-19. 
4. Dal Ferro, N., Delmas, P., Duwig, C., Simonetti, G., Morari, F., "Coupling X-ray microtomography and mercury intrusion porosimetry to quantify aggregate structures of a cambisol under different fertilisation treatments", Soil and Tillage Research, 119(2), 2012, pp. 13-21.

5. Monroy, R., Zdravkovic, L., Ridley, A., "Evolution of microstructure in compacted London Clay during wetting and loading”, Géotechnique, 60(2), 2010, pp. 105-119.

6. Wei, X., Hattab, M., Fleureau, J. M., Hu, R., "Micro-macroexperimental study of two clayey materials on drying paths", Bulletin of Engineering Geology and the Environment, 72(3-4), 2013, pp. 495-508.

7. Aldaood, A., Bouasker, M., Al-Mukhtar, M., "Impact of freezethaw cycles on mechanical behaviour of lime stabilized gypseous soils", Cold Regions Science and Technology, 99(1),2014, pp. 3845.

8. Burton, G. J., Pineda, J. A., Sheng, D., Airey, D., "Microstructural changes of an undisturbed, reconstituted and compacted high plasticity clay subjected to wetting and drying", Engineering Geology, 193, 2015, pp. 363-373.

9. Yuan, S Liu, X Sloan, S W Buzzi, O, P "Multi-scale characterization of swelling behaviour of compacted Maryland clay", Acta Geotechnica, 2016, pp.1-16.

10. Wu, Z., Deng, Y., Liu, S., Liu, Q., Chen, Y., Zha, F., "Strength and micro-structure evolution of compacted soils modified by admixtures of cement and metakaolin", Applied Clay Science, 127, 2016, pp. 44-51.

11. Simms, P. H., Yanful, E. K., "Measurement and estimation of pore shrinkage and pore distribution in a clayey till during soil-water characteristic curve tests", Canadian Geotechnical Journal, 38(4), 2001, pp. 741-754.

12. Simms, P. H., Yanful, E. K., "A pore-network model for hydromechanical coupling in unsaturated compacted clayey soils", Canadian Geotechnical Journal, 42(2), 2005, pp. 499-514.
13. Hoffmann, C., Alonso, E. E., Romero, E., "Hydro-mechanical behaviour of bentonite pellet mixtures", Physics and Chemistry of the Earth, Parts $A / B / C, 32(8), 2007$, pp. 832-849.

14. Katti, D. R., Shanmugasundaram. V., "Influence of swelling on the microstructure of expansive clays", Canadian Geotechnical Journal, 38(1), 2001, pp. 175-182.

15. Lin, B., Cerato, A. B., Madden, A. S., Madden, M. E. E., "Effect of Fly Ash on the Behavior of Expansive Soils: Microscopic Analysis", Environmental \& Engineering Geoscience, 19(1), 2013, pp. 85-94.

16. Zhang, G., Germaine, J. T., Whittle, A. J., "Drying induced alteration to the microstructure of a tropical soil", In: Proceedings of International Symposium on advanced experimental unsaturated soil mechanics, Trento, Italy, 2005, pp. 443-449.

17. Garcia-Guinea, J., Recio-Vazquez, L., Almendros, G., Benavente, D., Correcher, V., Perez-Garcia, A., ... Fernandez-Cortes, A., "Petrophysical properties, composition and deterioration of the Calatorao biogenic stone: case of the sculptures masonry of the Valley of the Fallen (Madrid, Spain)", Environmental earth sciences, 69(5), 2013, pp. 1733-1750.

18. Tang, Y., Yan, J., "Effect of freeze-thaw on hydraulic conductivity and microstructure of soft soil in Shanghai area", Environmental Earth Sciences, 73(11), 2015, pp. 7679-7690.

19. Tang, H., Li, C., Hu, X., Wang, L., Criss, R., Su, A., ... Xiong, C. "Deformation response of the Huangtupo landslide to rainfall and the changing levels of the Three Gorges Reservoir", Bulletin of Engineering Geology and the Environment, 74(3), 2015, pp. 933942.

20. Hu, X. L., Tang, H. M., Li, C. D., Sun, R. X., "Stability of Huangtupo I I $^{\#}$ dslide under Three Gorges Reservoir Operation", Applied Mechanics \& Materials, 170-173, 2012, pp. 1116-1123.

21. Hu, X. L., Tang, H. M., Li, C. D., Sun, R. X., 'Stability of Huangtupo riverside slumping mass $\mathrm{II}^{\#}$ under water level fluctuation of Three Gorges Reservoir', Journal of Earth Science, 23(3), 2012, pp. 326-334 